\title{
World Cup 2010 and acute pain in the neck
}

\author{
W A Mann, K Jungheim
}

To the Editor: Vuvuzelas are a new experience for non-South African soccer fans, and for their physicians. We describe the first case of a vuvuzela-induced thyroid cyst. A 42-year-old man presented with acute painful swelling of the neck and difficulty in swallowing. An ultrasound scan confirmed the clinical suspicion of a thyroid cyst with a volume of $2 \mathrm{ml}$ (Fig. 1). The cyst was successfully emptied by fine-needle aspiration (Fig. 2) and the patient was immediately free of complaints. On being asked whether he had raised heavy weights or pressed strongly, he responded that he had blown a vuvuzela during a recent World Cup soccer game.

Thyroid cysts may appear spontaneously, and frequently the medical history includes heavy pressing or related activities, which result in an increase in intrathoracic pressure. Valsalva-like procedures increase central venous pressure. For example, playing high notes on a trumpet, which belongs to the group of high-resistance instruments that includes the vuvuzela, may increase intrathoracic pressure up to $200 \mathrm{~cm} \mathrm{H}_{2} \mathrm{O}$. Exposure to this degree of pressure can reversibly decrease cardiac silhouette by one-third and significantly decrease pulmonary vasculature signs on chest radiographs. ${ }^{1}$

The soccer World Cup in South Africa was dominated acoustically by the sound of the African horn, called the vuvuzela. Over the past 15 years this instrument, originally made from the kudu horn and later from plastic, has become much beloved by keen soccer supporters and also a symbol of hope and unity. ${ }^{2}$

Before the World Cup the hearing risks posed by the vuvuzela were reported. ${ }^{3}$ The maximum sound level produced may reach $131 \mathrm{~dB}$, comparable to a compressed air-hammer. According to World Health Organization recommendations exposure to noise at sport or leisure events should be limited to $100 \mathrm{db}$, and this led to the suggestion of preventive measures such as hearing protection. ${ }^{4}$

A press release from the London School of Hygiene and Tropical Medicine also discussed the formation of potentially infectious aerosols distributed together with the typical sound when the instrument is blown. ${ }^{5}$

No data on vuvuzela-induced thyroid cysts could be found in the literature.

\section{References}

1. Muhar F, Coblenzer H. Atemmechanische Aspekte bei der Phonation. Lung 1967;135:309-321.

Endokrinologikum Frankfurt a.Main, Frankfurt, Germany

W A Mann, MD

K Jungheim, MD

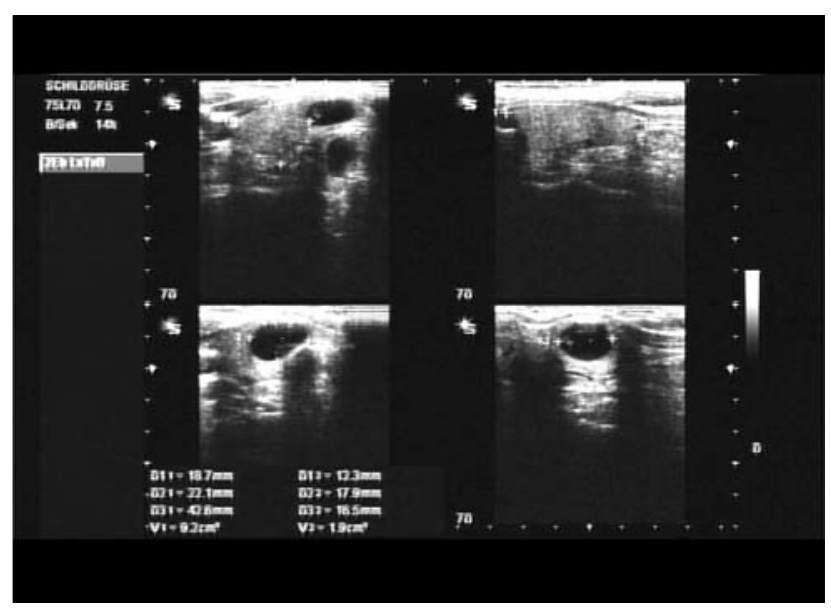

Fig. 1. Thyroid ultrasound scan showing a cyst in the isthmus region of the right thyroid lobe.

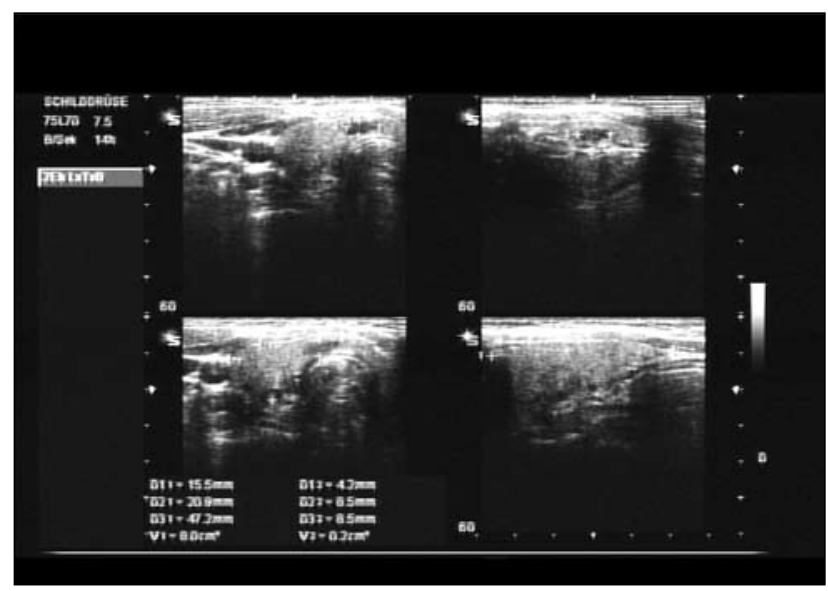

Fig. 2. Thyroid ultrasound scan after evacuation of the cyst by fine-needle aspiration.

2. Federation Internationale de Football Association (FIFA). Vuvuzela: a symbol of South Africa. http://www.fifa.com/confederationscup/news/newsid=1073689. html (accessed 29 June 2010).

3. Swanepoel DW, Hall JW, Koekemoer D. Vuvuzela - good for your team, bad for your ears. S Afr Med J 2010;100:99-100.

4. Berglund B, Lindvall T, Schwela DH, eds. Guidelines for Community Noise. World Health Organization, 1999. http://www.who.int/docstore/peh/noise/ guidelines2.html (accessed 29 June 2010).

5. McNerney R. http://www.1shtm.ac.uk/news/2010/vuvuzela-infections.html (accessed 29 June 2010). 